\title{
Targeting Astrocytes for Stroke Therapy
}

\author{
Yanxin Zhao and David A. Rempe \\ Department of Neurology in the Center for Neural Development and Disease, University of Rochester School of Medicine and \\ Dentistry, Rochester, New York 14642
}

\begin{abstract}
Summary: Stroke remains a major health problem and is a leading cause of death and disability. Past research and neurotherapeutic clinical trials have targeted the molecular mechanisms of neuronal cell death during stroke, but this approach has uniformly failed to reduce stroke-induced damage or to improve functional recovery. Beyond the intrinsic molecular mechanisms inducing neuronal death during ischemia, survival and function of astrocytes is absolutely required for neuronal survival and for functional recovery after stroke. Many functions of astrocytes likely improve neuronal viability during stroke. For example, uptake of glutamate and release of neurotrophins enhances neuronal viability during ischemia. Under certain conditions, however, astrocyte function may compromise neuronal viability. For example, astrocytes may produce
\end{abstract}

inflammatory cytokines or toxic mediators, or may release glutamate. The only clinical neurotherapeutic trial for stroke that specifically targeted astrocyte function focused on reducing release of S-100 $\beta$ from astrocytes, which becomes a neurotoxin when present at high levels. Recent work also suggests that astrocytes, beyond their influence on cell survival, also contribute to angiogenesis, neuronal plasticity, and functional recovery in the several days to weeks after stroke. If these delayed functions of astrocytes could be targeted for enhancing stroke recovery, it could contribute importantly to improving stroke recovery. This review focuses on both the positive and the negative influences of astrocytes during stroke, especially as they may be targeted for translation to human trials. Key Words: Astrocyte, stroke, ischemia, glutamate, inflammation, translation.

\section{TARGETING ASTROCYTES FOR STROKE THERAPY}

To date, interventions with small molecule pharmacological compounds meant to provide neuroprotection during focal stroke have invariably used strategies that target mechanisms of neuronal cell death occurring within minutes to a few hours after the onset of ischemia. If a neuroprotective agent is to reduce stroke volume, however, it also must reduce cell death of multiple cell types, including astrocytes, oligodendrocytes, and endothelial cells of the cerebral vasculature. In fact, given that astrocytes outnumber neurons by severalfold in the human brain, protection and maintenance of astrocyte function during focal stroke may be more important than that of neurons. Regardless, any putative neuroprotective agent that targets only neuronal cell death, but does not reduce astrocyte cell death or take into consideration its effects on astrocyte function, cannot be effective. Beyond simply their survival, interactions of neurons, glia,

Address correspondence and reprint requests to: David A. Rempe, M.D., Ph.D., Department of Neurology in the Center for Neural Development and Disease, University of Rochester School of Medicine, 601 Elmwood Avenue, Rochester, NY 14642. E-mail: david_rempe@urmc.rochester.edu. and the vasculature are being conceptualized as a neurovascular unit, which is becoming recognized as importantly contributing to a number of neurological diseases, including stroke. ${ }^{1}$ In that light, future stroke therapies need to broaden the scope of neuroprotection to develop strategies to maintain function and survival of the entire neurovascular unit.

Astrocytes are involved in a number of activities that profoundly influence tissue viability during ischemia, including glutamate homeostasis, water balance, maintenance of the blood-brain barrier, cerebral blood flow regulation, ion homeostasis, and secretion of neuroprotective factors $^{2-6}$ (see the article by Kimelberg and Nedergaard in this issue). Although astrocyte function is clearly necessary for maintenance of neuronal health, certain functions of astrocytes can have pathological consequences after stroke. For example, astrocyte participation in inflammatory processes and their production of potential neurotoxic substances, such as S-100 $\beta$, can enhance stroke volume. Beyond their influence on neuronal cell death during stroke, astrocytes also likely play critical roles during functional recovery after stroke. Several expert reviews discuss these numerous aspects of astrocyte function and death during stroke. ${ }^{4,7-15}$ Here, we will briefly review mechanisms of 
astrocyte cell death during stroke, but focus most of the discussion on the adaptive and pathological roles of astrocytes during ischemia. Where applicable, we will discuss the potential for targeting astrocyte function to reduce cell death during stroke and so improve functional recovery.

\section{MECHANISMS OF ASTROCYTE CELL DEATH IN STROKE}

Many of the pathological pathways that are induced during ischemia that cause neuronal death, such as reactive oxygen species (ROS), also cause astrocyte death; however, differences exist in the mechanisms by which neurons and astrocytes die during ischemia. Complete cerebral blood flow cessation causes irreversible injury to all cell types in the ischemic core, including neurons and astrocytes, because the supply of glucose and oxygen ceases. In contrast, in the ischemic penumbra, where oxygen and glucose delivery is partly maintained, astrocytes may survive for a prolonged period. ${ }^{4}$

It is well appreciated that, compared with neurons, cultured astrocytes are more resistant to oxygen and glucose deprivation (OGD). ${ }^{16}$ One hour of OGD caused significant necrosis in neuronal culture, yet had no obvious effect on astrocytes culture. ${ }^{17}$ Furthermore, unlike neurons, cultured astrocytes withstand prolonged hypoxia, provided that glucose is available. ${ }^{16,18,19}$ This finding demonstrates the ability of astrocytes to use glycolysis to produce ATP. However, enhanced glycolysis increases production of lactic acid, which may result in acidosis. When the $\mathrm{pH}$ falls below 6.6, glycolysis ceases and astrocytes suffer irreversible cell death. In fact, compared with neurons, astrocytes are particularly sensitive to acidosis. ${ }^{20,21}$ Modeling the ion shifts that occur during stroke in combination with hypoxia and acidosis indicates that irreversible injury to astrocytes occurs in time frames as short as 15 minutes. ${ }^{8}$ Thus, under certain conditions, astrocyte viability may be compromised very quickly in the brain, despite the relative resistance to OGD in vitro. Although in the stroke core ischemic cell death occurs very quickly, delayed increases in infarct volume are observed under some conditions. The function of astrocytes likely mediates both adaptive and pathological roles during this delayed time period, but the extent to which astrocyte cell death itself contributes to this change in stroke volume is uncertain. Nonetheless, caspase activation and apoptosis of astrocytes could contribute to delayed astrocyte death. ${ }^{11}$

The relative vulnerability in vivo of astrocytes and neurons during stroke is still an open question. Some in vivo studies of focal cerebral ischemia suggest that astrocytes may be more vulnerable than neurons, ${ }^{22,23}$ and indeed certain subtypes of astrocytes, such as protoplasmic astrocytes, may be particularly vulnerable during stroke. ${ }^{22,24}$ In contrast, however, a recent report suggests that astrocyte viability is maintained longer than neurons during ischemia. ${ }^{25}$ Regardless, it is appreciated that, although astrocytes and neurons share sensitivity to some injurious stimuli, there are also important differences in the causes of neuronal versus astrocyte cell death during stroke, such as the sensitivity of astrocytes to acidosis but resistance to glutamate excitotoxicity. Because neurons are not viable without astrocytes, if future neurotherapeutics are directed solely at neuronal mechanisms of cell death without consideration of astrocyte viability then they cannot succeed. ${ }^{4}$

\section{AN INTRODUCTION TO THE ADAPTIVE AND PATHOLOGICAL ROLES OF ASTROCYTES IN DELAYED STROKE VOLUME GROWTH}

Even if a successful therapy is devised to reduce stroke damage during the acute phase of stroke, inevitably the therapy will fail a majority of patients who present beyond the acute treatment window. Over the past several years, accumulating data from animal models and human studies suggest that the peri-infarct cortex is a dynamic region that can be incorporated into the infarct territory several hours to days after stroke. This growth in stroke volume likely contributes to poorer outcomes. ${ }^{26}$ Delayed growth of the ischemic infarct likely depends on the length of ischemia. For example, one report described a dramatic increase in stroke volume after 30 minutes of transient middle cerebral artery occlusion (MCAO), which became manifest more than a day after the infarct. ${ }^{27}$ When ischemia was applied for a longer time frame (90 minutes), however, the infarct damage was maximal within 24 hours after stroke. ${ }^{27}$ More typically, a delayed increase in stroke volume is much more subtle or absent in rodent models ${ }^{13,28,29}$; however, a notable increase in infarct growth may be observed when neuroprotective mechanisms are impaired in the brain, an illustration of the tenuous nature of cell viability in the penumbra. ${ }^{28,29}$

Factors such as the presence of edema, peri-infarct depolarizations, ${ }^{30-32}$ inflammatory changes, ${ }^{33-35}$ or the amount of collateral blood flow likely determine the fate of the penumbra. In addition, expression and release of neuroprotective or harmful substances in response to ischemia are also likely determinants of cell death. ${ }^{13,29,35}$ Given that astrocytes modulate blood flow, contribute to water homeostasis, participate in inflammatory responses, maintain ion homeostasis, and release a number of substances that may be either neuroprotective or harmful, they undoubtedly contribute to determining the viability of this vulnerable tissue.

In certain situations, astrocytes may negatively affect the balance of life and death in the vulnerable penumbra. For example, release of potentially toxic factors (e.g., 
S-100 $\beta$ ) or participation in inflammatory processes could contribute to stroke growth. ${ }^{13}$ After some ischemic insults, such as permanent MCAO and transient global ischemia, reactive astrocytes express inducible nitric oxide synthase (iNOS), which produces nitric oxide (NO), a known neurotoxin. ${ }^{36}$ The induction of iNOS occurs within a time frame when delayed growth in infarct volume is typically observed. ${ }^{37}$ More importantly, although no difference in stroke volume is observed in iNOS knockout mice 24 hours after stroke, iNOS knockout mice do have reduced stroke volumes 96 hours after stroke. ${ }^{35}$ Thus, iNOS contributes to delayed infarct growth after MCAO. Despite the fact that astrocytes express iNOS after transient global ischemia, ${ }^{36}$ the specific role of astrocytes in the delayed infarct growth after focal ischemia is undefined, given that other cell types (including polymorphonuclear cells) also highly express iNOS. ${ }^{37}$

Transcription factors and gene regulation also influence delayed cell death in the peri-infarct cortex. Loss of activity of the transcription factor hypoxia-inducible factor-1 (HIF-1) specifically in neurons enhances infarct growth 24-96 hours after stroke onset. ${ }^{29}$ HIF-1 is expressed at low levels when oxygen availability is not limited, but its protein abundance is markedly induced during hypoxia. Once stabilized, HIF-1 translocates to the nucleus and induces a large number of targets that increase adaptive responses, such as glycolytic enzymes, neuroprotectants (erythropoietin [EPO] and adrenomedullin), and factors that encourage angiogenesis (vascular endothelial growth factor [VEGF]). ${ }^{29,38}$ Thus, at least in neurons, HIF-1 has an adaptive function that impedes growth of stroke volume during this delayed time frame. In neuronastrocyte cocultures, however, HIF-1 activity in astrocytes has the opposite effect on neuronal viability. ${ }^{18}$ That is, loss of HIF-1 function selectively in astrocytes greatly reduces hypoxia-induced neuronal death in cocultures. Similar to the neuron-specific loss of HIF-1 in vivo, selective loss of HIF-1 function in neurons in astrocyteneuron cocultures augments hypoxia-induced neuronal death. Thus, HIF-1 expressed in neurons reduces hypoxia cell death, but it has the opposite effect when expressed in astrocytes. Whether this cell-type-specific effect of HIF-1 in astrocytes occurs in vivo after stroke is yet to be determined. Nonetheless, it is important to delineate the cell-type-specific effects of ischemia-induced gene expression changes in future work, to determine if they may have opposing effects in divergent cell types.

In contrast to the potential pathological roles of astrocytes in stroke, astrocytes also release a number of neuroprotectants, including EPO, VEGF, and glial derived neurotrophic factor, all of which can either reduce ischemic neuronal damage or improve functional recovery after stroke. ${ }^{39-44}$ Another potential neuroprotective ac- tion of astrocytes during stroke is the increase in extracellular adenosine provided by release of ATP by astrocytes. The ATP is subsequently converted to adenosine, which has neuroprotective properties. These divergent pathological and neuroprotective functions of astrocytes and their potential for translation to neurotherapeutics are addressed in detail in the rest of this review.

\section{POTENTIAL PATHOLOGICAL ROLES OF ASTROCYTES DURING ISCHEMIA}

Astrocyte function importantly contributes to cell survival in the tenuous ischemic penumbra during stroke, both early after the onset of ischemia and during the delayed time frame days to weeks after stroke. FIG. 1 schematically illustrates the multiple actions by which astrocytes likely contribute to neuronal death in the penumbra early and late after stroke onset.

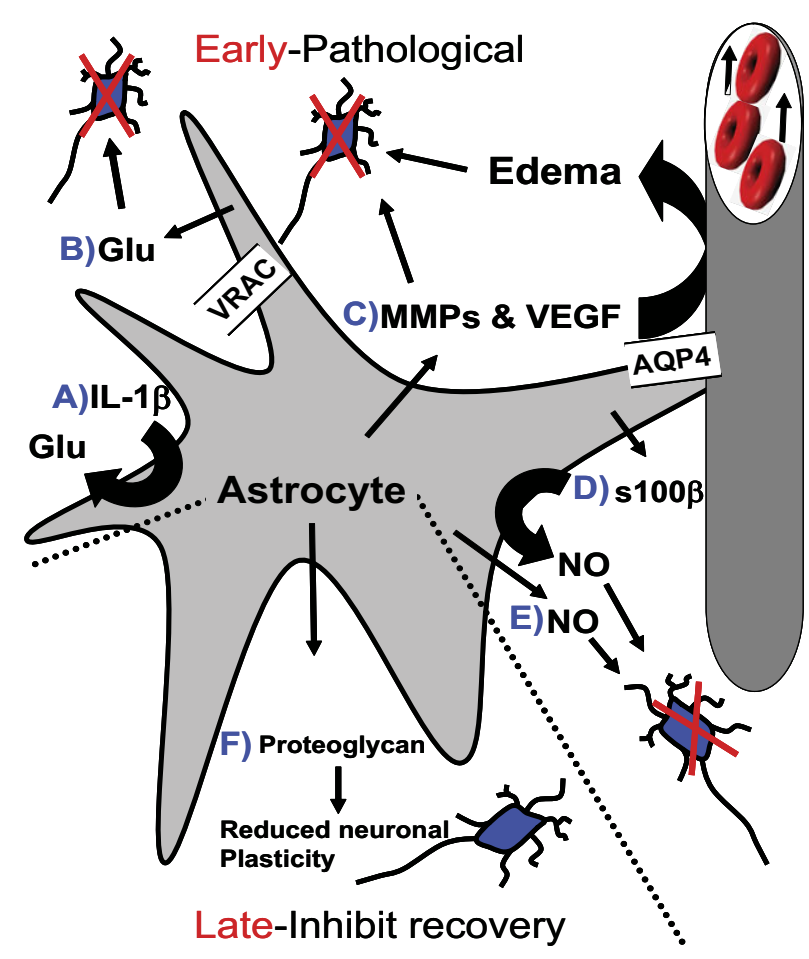

FIG. 1. A schematic representation of the pathological effects of astrocytes on neuronal survival and plasticity early (above dotted line) and late (below dotted line) after onset of stroke. Potential pathological effects of astrocyte early after stroke include release of glutamate (Glu) induced by inflammatory signals (interleukin $1 \beta, I L-1 \beta)(A)$ or through volume-regulated anion channels (VRAC) (B). Brain edema is induced by multiple mechanisms including aquaporin 4 (AQP4), vascular endothelial growth factor (VEGF), and matrix metalloproteinase (MMP) (C). In addition, MMPs also have direct injurious effects on neurons. Release of $\mathrm{S}-100 \beta$ by astrocytes at high levels is toxic to neurons (D). Release of nitric oxide (NO) by astrocytes, which $\mathrm{S}-100 \beta$ may contribute to, is injurious to neurons $(E)$. During later time courses after stroke, scar formation by astrocytes and expression of proteoglycans impede neurite outgrowth and plasticity limiting functional recovery from stroke $(F)$. 


\section{Astrocytes, edema, and volume regulation in stroke}

Astrocytes are key regulators of brain edema, which is an important determinant of patient survival after severe stroke. ${ }^{45}$ Moreover, in the tenuous penumbra, edema likely further reduces blood flow, leading to still further cellular compromise (FIG. 1C). The aquaporins are specialized water channel proteins through which water is transported. Aquaporin 4 (AQP4) is highly expressed on astrocyte end-feet near the cerebral vasculature. ${ }^{46-48}$ This position of AQP4 gives astrocytes a central role in determining water content in the brain during pathological processes such as stroke. It might be predicted that water could enter AQP4 channels and contribute to cytotoxic edema during stroke. In fact, AQP4 knockout mice have reduced cytotoxic edema during stroke. ${ }^{49}$ Thus, inhibition of AQP4 channel function could reduce edema during stroke, and this is a target for drug development. In addition, reduced abundance of AQP4 diminishes the function of volume-regulated anion channels (VRAC) in astrocyte cultures ${ }^{50}$ which could account for some of its protective effects. Notably, because AQP4 also enhances astrocyte migration and glial scar formation, AQP4 inhibitors may also be useful to reduce glial scar formation. Currently, however, specific inhibitors of the AQP4 channel do not exist. ${ }^{46}$

Astrocytes undergo rapid swelling in ischemic brain injury, which contributes to astrocyte dysfunction during stroke. ${ }^{5}$ Several mechanisms could account for astrocyte swelling during ischemia, including decreased osmolarity, Donnan swelling, acidosis, glutamate uptake, and the $\mathrm{Na}^{+}, \mathrm{K}^{+}, 2 \mathrm{Cl}^{-}$cotransporter. ${ }^{5}$ Astrocyte swelling may be detrimental to neuronal survival by inducing glutamate release from astrocytes via VRACs ${ }^{5}$ (FIG. 1B), which function to counteract the imposed osmotic gradients and facilitate the recovery to their normal size; VRACs may also contribute to the release of glutamate in the cortical penumbra region. For example, tamoxifen, an inhibitor of VRAC function, reduces the average glutamate release in the penumbra region in rodent models by approximately 50\%. ${ }^{51}$ Tamoxifen, administered up to 3 hours after the onset of ischemia, also reduces stroke volume and improves behavioral recovery after $\mathrm{MCAO}^{52}$. Nonetheless, although tamoxifen counteracts astrocyte swelling, it has other prominent effects, and recent work suggests that it likely reduces stroke volume primarily through its ability to reduce ROS. ${ }^{53}$

\section{Inflammation and hypoxia influence glutamate homeostasis by altering astrocyte function}

As described above, inflammation is an important determinant of stroke-induced damage and functional recovery in the subacute phase of stroke. Inhibiting inflammatory processes such as cyclooxygenase-2 (COX-2) and iNOS reduces delayed growth of stroke volume in animal models. ${ }^{33,35}$ Thus, several inflammatory signaling cascades are a target of translational research for stroke. ${ }^{54}$ Astrocytes participate in the immune response in various ways, including release of cytokines and chemokines. ${ }^{55}$ In addition, signaling between astrocytes and microglia has important consequences for neuronal viability (see also the articles by Yenari, Kauppinen, and Swanson, by Loane and Byrnes, and by Lull and Block, in this issue). For example, during HIV-associated neuroinflammation, TNF- $\alpha$ derived from microglia and stromal derived factor- 1 cooperate to induce release of glutamate from astrocytes leading to excitotoxicity. ${ }^{56}$

The importance of astrocytes in maintaining extracellular glutamate homeostasis is well appreciated. Glutamate is transported into astrocytes from the extracellular space through the excitatory amino acid transporters EAAT2 (alias GLT-1) and EAAT1 (alias GLAST). ${ }^{57}$ Not surprisingly, loss of these glutamate transporters increases neuronal death in vivo. ${ }^{58}$ Thus, after stroke, compromise of glutamate transport into astrocytes may lead to excitotoxicity. Inflammatory signaling and hypoxia, singly or in combination, contribute to compromise of glutamate homeostasis by astrocytes. In astrocyte cultures, hypoxia downregulates the expression of the glutamate transporters EAAT1 and EAAT2. ${ }^{59,60}$ This hypoxia-induced reduction in glutamate transporter expression is mediated by the transcription factor NF- $\kappa \mathrm{B}$, which is induced by both hypoxia and inflammatory signals. ${ }^{61,62}$ Similarly to hypoxia, the inflammatory cytokine $\mathrm{TNF} \alpha$ also reduces EAAT2 expression in astrocytes. ${ }^{63}$

It is possible that enhancing the EAAT2 abundance in astrocytes could reduce excitotoxicity in stroke and neurodegenerative diseases. A screen to identify drugs that induce EAAT2 demonstrated that the $\beta$-lactam antibiotics, especially ceftriaxone (CFX), increase the expression of EAAT2 in organotypic spinal cord slice cultures. ${ }^{64}$ Moreover, CFX protects against oxygen-glucose deprivation in mixed neuron-astrocyte cultures. ${ }^{64}$ To test the ability of CFX to protect against ischemia, rats were pretreated with CFX for 5 days prior to transient MCAO. The CFX treatment reduced stroke volume and increased EAAT2 expression in this paradigm. ${ }^{65}$ This CFX-mediated protection was reversed by a selective EAAT2 inhibitor, suggesting that the protection was mediated by EAAT2 function. However, because CFX induces the expression of the transcription factors NF- $\kappa \mathrm{B}$ and Nrf2, CFX may protect against cell death through multiple mechanisms. ${ }^{66,67}$ In contrast to its administration before stroke, administration of CFX 30 minutes after the onset of ischemia did not significantly reduce stroke volume. ${ }^{65}$ This lack of protection is not surprising, given that glutamate excitotoxicity is such an early event after onset of ischemia. Moreover, astrocytes experiencing severe energy failure could release more glutamate if EAAT is expressed at a higher level. For these reasons, CFX is unlikely to be used clinically for stroke. Nonetheless, 
treatment with CFX may be applicable for treatment of neurodegenerative diseases such as ALS (see the reviews by Hamby and Sofroniew and by Vargas and Johnson in this issue).

Inflammation-induced release of glutamate by astrocytes may also contribute to neuronal death during stroke. Multiple past studies, using blocking antibodies, antagonist, viral vectors, and genetic methods, demonstrated that the inflammatory cytokine interleukin- $1 \beta$ (IL-1 $\beta$ ) contributes to stroke-induced brain damage. ${ }^{68-73}$ Similarly, ubiquitous loss of IL-1R1 receptor function reduced stroke volume in mice. ${ }^{69}$ Because microglia are a key source of IL-1 $\beta$ in the brain (see the articles by Loane and Byrnes, by Lull and Block, and by Yenari, Kauppinen, and Swanson in this issue), they undoubtedly play a key role in this pathological effect. However, signaling of IL- $1 \beta$ through astrocytes may also contribute to neuronal death. For example, a study using cocultures of neurons and astrocytes demonstrated that IL- $1 \beta$ signaling through the IL-1R1 receptor on astrocytes induces neuronal death. ${ }^{69}$ Using exposure to a combination of hypoxia and IL- $1 \beta$, the authors selectively induced neuronal death in the cocultures (FIG. 1A). Notably, IL-1R1 expression on astrocytes, but not neurons, was required for neuronal injury to be evoked by the combination of hypoxia and IL- $1 \beta .^{69}$ This neuronal death was mediated by release of glutamate through system $X_{c}$ in astrocytes.

Given the evidence of IL- $1 \beta$ contributing to stroke pathology, a recent double-blind, placebo-controlled safety trial targeted IL-1R function for the treatment of stroke patients. ${ }^{74}$ Animal studies demonstrated that a naturally occurring selective antagonist of the IL-1 receptor (IL-1ra) reduced stroke volume and disability when administered for up to 3 hours after onset of MCAO in rats. ${ }^{72}$ Similarly, treatment with IL-1ra was initiated within 6 hours of stroke onset in stroke patients and was continued for 72 hours. ${ }^{74}$ No increased adverse events were observed in the treatment group, compared with placebo. Although the study was not powered to determine efficacy, in the patients with cortical strokes, the IL-1ra group tended to have better outcomes. This potentially beneficial effect of IL1ra will need to be confirmed in larger efficacy trials.

\section{Astrocytes, S-100ß, and delayed stroke volume growth}

To date, we are aware of only one clinical trial specifically targeting astrocyte function as a means to diminish stroke-induced damage. This trial tested the ability of arundic acid (AA) (ONO-2506) to protect against stroke. As already noted, astrocytes may have pathological properties that lead to enhanced infarct growth in the days after stroke. One of the mechanisms by which astrocytes could enhance neuronal death after stroke is through release of S-100 $\beta$ (FIG. 1D). S-100 is a calcium binding protein consisting of $\alpha$ and $\beta$ subunits. $\mathrm{S}-100 \beta$ is expressed in astrocytes and is released into the serum and CSF 24-96 hours after onset of ischemic stroke. ${ }^{75} \mathrm{Al}-$ though at low doses S-100 can be neuroprotective, high levels of S-100 induce neuronal and astrocyte cell death. $\mathrm{S}-100 \beta$ abundance is markedly increased in the CSF prior to delayed stroke volume expansion, ${ }^{75}$ suggesting a potential pathological role of S- $100 \beta$ in stroke volume expansion. Although the pathological effects of S- $100 \beta$ are likely multifactorial, a primary mechanism by which $\mathrm{S}-100 \beta$ is pathological is likely through increased release of NO by astrocytes after exposure to $S-100 \beta .^{76}$

To target the induction and release of $\mathrm{S}-100 \beta$ by astrocytes, in vitro screens of chemical compounds were performed to identify compounds that diminish activation of astrocytes and S- $100 \beta$ expression. In this screening, AA was found to effectively diminish expression and release of S-100 $\beta$ in astrocyte cultures. ${ }^{13}$ Rodent stroke models confirmed that AA diminished S-100 $\beta$ abundance in CSF 24 hours after permanent focal ischemia or transient focal ischemia models in rodents, when administered immediately after stroke. ${ }^{77}$ Immediate treatment with AA also diminished ischemic stroke volume and improved functional outcome 7 days after stroke onset. Given that $\mathrm{S}-100 \beta$ abundance does not peak for 24-72 hours after the onset of brain ischemia, it would be predicted that administration of AA several hours after onset of ischemia might still have a protective effect. In fact, delayed administration of AA at 24 hours after stroke onset reduced delayed infarct growth, and improved stroke outcome suggesting a prolonged window of efficacy. Notably, the protective effect of AA was greater if administered 24 hours after stroke onset, compared with its administration immediately after stroke onset, suggesting that its window of efficacy is very much extended, relative to that of most neuroprotectants.

Although AA was first developed for its ability to reduce activation of astrocytes and expression of S-100 $\beta$, it likely has pleiotropic effects. For example, AA reduces inflammatory mediators, including iNOS and COX-2, while also inducing glutamate transporters and $\mathrm{GABA}_{\mathrm{A}}$ receptors on astrocytes (for review see Asano et al. ${ }^{13}$ ). Finally, looking beyond the beneficial effects in rodent models, AA was also tested in nonhuman primates. Although these data were presented only in abstract form (cited by Asano et al. ${ }^{13}$ ), AA reportedly reduced stroke volume and disability in nonhuman primates when administered several hours after stroke onset. Finally, AA administered to stroke patients reduced the serum levels of S-100 $\beta$ after stroke, suggesting that AA could have efficacy in clinical stroke. ${ }^{78}$

Given the promising preclinical data, a clinical trial testing the tolerability of AA in acute stroke patients was conducted. ${ }^{79}$ The criteria for inclusion of patients in this initial clinical trial required an NIH stroke scale (NIHSS) 
score of 7-22, to focus on patients with moderate stroke volumes, who may be more likely to benefit from therapeutic intervention. Arundic acid was infused daily over 1 hour for 7 days after stroke onset, at doses ranging from 2 to $12 \mathrm{mg} / \mathrm{kg}$ per hour. Although it was not an efficacy trial, the group of patients receiving $8 \mathrm{mg} / \mathrm{kg}$ per hour appeared to gain therapeutic benefit; however, neither the lower doses $(2,4$, or $6 \mathrm{mg} / \mathrm{kg}$ per hour), or higher (10 or $12 \mathrm{mg} / \mathrm{kg}$ per hour) doses, appeared to benefit from treatment. A multiple-center trial testing the efficacy of AA to reduce stroke related disability was conducted, but this trial was terminated early for lack of efficacy. Arundic acid is still being tested for efficacy in other neurological diseases, such as ALS (see the article by Vargas and Johnson in this issue), in which astrogliosis may have a prominent effect on outcome. Given this lack of efficacy of AA in stroke, despite the compelling preclinical data, it is important to consider whether delayed growth of stroke volume occurs in humans and whether it is a worthy target for therapeutic intervention.

\section{Delayed stroke volume growth in humans: a target for intervention?}

Arundic acid was developed to reduce the pathological effects of $S-100 \beta$ release by astrocytes to minimize delayed growth of stroke volume. Given the lack of efficacy of AA in treating stroke, it is important to consider whether delayed infarct growth occurs in humans, and if it is important for determining clinical outcome. Although this has not been extensively studied, some studies suggest a delayed increase in infarct volume in stroke patients. ${ }^{26,80,81}$ By using serial MRI imaging of patients after stroke, these studies suggest an increase in stroke volume several hours to days after stroke onset. Using diffusion-weighted imaging, which is thought to correlate with the core of the infarct and nonrecoverable tissue, ${ }^{82}$ the size of lesions on diffusion-weighted imaging increases in $85-95 \%$ of patients. ${ }^{26,80,81}$ Two studies, which serially imaged 14 and 21 patients each, suggested an increase in infarct volume that did not maximize until 3-5 days after the onset of ischemia. ${ }^{81,83}$

Of course, even if infarct volume increases over time, this does not necessarily indicate that growth in infarct size will affect functional outcome after stroke. Recent work has begun to address this important question. The relationship between functional recovery and delayed stroke volume growth was explored in 169 patients as a substudy of the Acute Stroke Accurate Prediction (ASAP) trial. ${ }^{26}$ Diffusion-weighted images were obtained less than 24 hours after stroke onset (median, 14 hours) and again 3-5 days after stroke onset (median, 3.6 days). Clinical outcome was evaluated 3 months after the stroke. Consistent with prior studies, approximately $85 \%$ of patients had measureable infarct growth from the first to the second MRI. The authors calculated the volume of infarct growth between the two time points and found a direct correlation between growth in infarct volume during this delayed time frame and clinical outcome at 3 months after stroke. That is, the greater the growth of the stroke volume between 14 hours and 3-4 days after stroke, the more severe the stroke-related disability.

More information will be needed before determining which patient populations may be most at risk of delayed infarct growth and therefore benefit from therapeutic intervention. First, it will be important to determine if the severity of the stroke is important in determining the degree of infarct growth. For example, the patients in the ASAP substudy had modest infarct volumes with a mean NIHSS score of $6,{ }^{26}$ which indicates a relatively mild stroke, compared with mean NIHSS score of 14 found in patients in the NINDS tPA (tissue plasminogen activator) trial. ${ }^{84}$ Thus, it is unclear whether delayed growth of infarct volume will correlate with clinical outcome in patients presenting with larger strokes, which are more frequently enrolled in clinical trials (including the trial testing AA). It is also important to note that only $29 \%$ of patients had growth in the stroke volume of greater than $10 \mathrm{~cm}^{3}$. It is this group, of course, that would most likely benefit from neuroprotective treatments designed to diminish delayed infarct growth. In animal models, the length of ischemia and its severity likely determine the degree to which delayed infarct growth is observed. ${ }^{27}$ Deciphering how to predict which patients will have the greatest infarct growth based on imaging criteria, or clinical presentation, would significantly strengthen our ability to intervene and reduce delayed increases in stroke volume in future neuroprotective trials.

\section{POTENTIAL ADAPTIVE ROLES OF ASTROCYTES DURING ISCHEMIA}

The previous section focused on the pathological effects of astrocytes function on neuronal survival in ischemia, but certain astrocyte functions also improve cellular survival in the penumbra, both early and later (days to weeks) after onset of ischemia. FIG. 2 schematically illustrates these multiple adaptive actions of astrocytes in the penumbra early and late after stroke onset.

\section{Astrocytes and EPO as a neuroprotectant}

Erythropoietin is a protein with neuroprotectant properties, and astrocytes are a main source of EPO in the brain. ${ }^{85-88}$ Recent reports suggest that another HIF family member, HIF-2, is the major inducer of EPO in hypoxia. ${ }^{39,89}$ Not only does EPO production by astrocytes have local effects, but ablation of HIF-2 function selectively in astrocytes causes anemia during hypoxia-ischemia, demonstrating the importance of astrocyte EPO production for erythropoiesis. $^{90}$

Several studies suggest a neuroprotective role for EPO 


\section{Early-Neuroprotective}

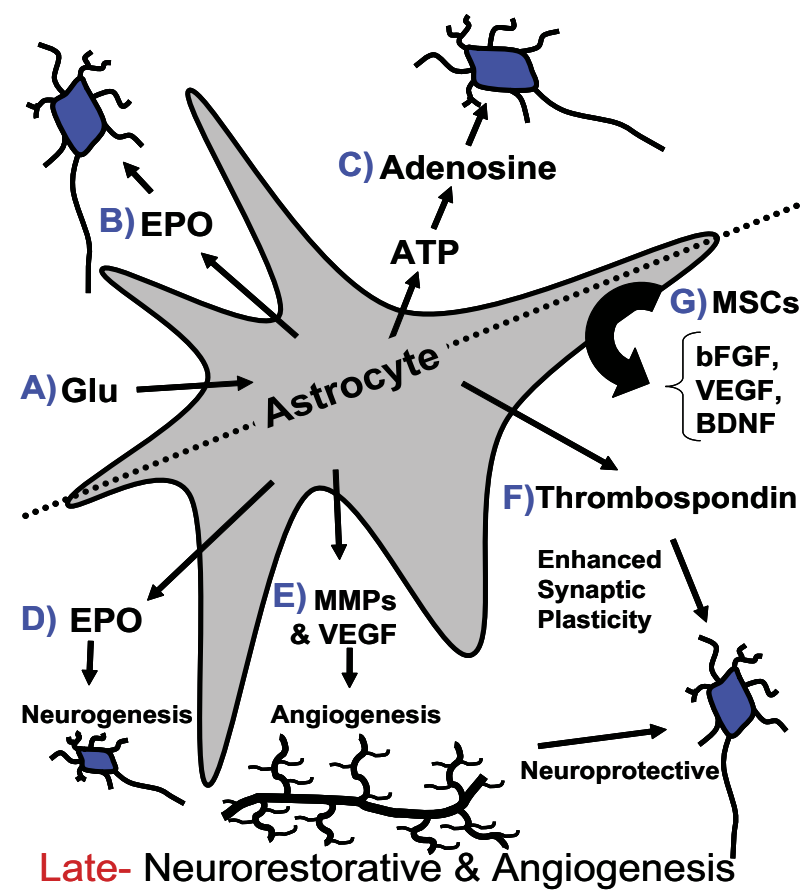

FIG. 2. A schematic diagram of the protective and adaptive effects of astrocytes on neuronal survival and plasticity early (above dotted line) and late (below dotted line) after onset of stroke. Early after stroke onset, several functions of astrocytes likely diminishes ischemia-mediated damage including uptake of glutamate (Glu) (A), release of erythropoietin (EPO) (B), and release of ATP which is converted to the neuroprotective compound adenosine $(C)$. In a later time frame (days to weeks) after ischemia, astrocytes perform multiple adaptive roles (below dotted line). For example, release of EPO likely enhances neurogenesis and is a neuroprotectant (D). MMP expression by astrocytes increases the abundance of activated VEGF, which increases angiogenesis and neuronal survival (E). Thrombospondin excretion by astrocytes enhances synaptic plasticity and recovery (F). Finally, administration of mesenchymal stromal cells (MSCs) induces the release of a number of neurotrophic factors by astrocytes (brainderived neurotrophic factor, BDNF; basic fibroblast growth factor, bFGF; vascular endothelial growth factor, VEGF), which enhances recovery from stroke $(G)$.

(FIG. 2B). Erythropoietin reduces neuronal death with OGD ${ }^{86}$ glutamate toxicity, ${ }^{91}$ and NO-induced cell death. ${ }^{92}$ Astrocytes contribute to the EPO-mediated neuroprotection, as demonstrated by experiments in which conditioned media taken from hypoxic astrocyte cultures is protective to neurons exposed to OGD. ${ }^{39}$ To reduce ischemic damage in the brain, neuroprotectants would need to reduce cell death of both neurons and astrocytes. On this note, it is interesting that not only does EPO protect neurons, but it also enhances viability of astrocytes exposed to $\mathrm{NO}$ or experiencing oxidative stress. ${ }^{93,94}$ Similar to the in vitro experiments, protective effects have been described for EPO in vivo during stroke. ${ }^{87,92,95,96}$ Hypoxic preconditioning is the observation that a sublethal exposure of mice to noninjurious mild hypoxia 48-72 hours prior to MCAO reduces stroke volume. This exposure to hypoxia induces a number of molecular processes that represent endogenous neuroprotective pathways. Erythropoietin likely plays a prominent role in mediating the protection of hypoxic preconditioning. Intrathecal EPO receptor protein administration, which sequesters EPO and inhibits its activity, precludes the neuroprotective actions of hypoxic preconditioning in rat stroke models. ${ }^{87}$ Finally, in neonatal stroke models, EPO administration is neuroprotective, induces neurogenesis, and improves functional recovery. ${ }^{97,98}$ Taken together, this evidence suggests that astrocyte-derived EPO is a crucial mediator of neuronal viability and functional recovery during and after stroke in adults and neonates.

Given the encouraging data from multiple animal models as to the efficacy of EPO in reducing strokerelated damage and disability, clinical trials were performed to establish the safety and efficacy of EPO in stroke treatment. An initial phase II trial did not identify any safety concerns and suggested efficacy of EPO protection in acute stroke. ${ }^{99}$ A subsequent phase III doubleblinded, placebo-controlled trial enrolled 522 patients; the patients were treated with EPO within 6 hours of the onset of their symptoms and clinical outcome was evaluated at 30 and 90 days after stroke. ${ }^{100}$ Overall, EPO did not improve clinical outcome, compared with placebo. In fact, a higher percentage of patients treated with EPO died $(16 \%)$, compared with the placebo group (9\%). There was no one single cause of death related to the higher death rate in patients receiving EPO. One key difference between the phase II and III trials was the difference in the number of patients receiving tPA. Although only one patient received IPA in the initial study, $63 \%$ of patients received tPA in the phase III trial. ${ }^{100}$ Notably, in subgroup analysis the patients not receiving tPA and treated with EPO had a greater improvement in their NIHSS scores at 30 and 90 days after stroke, compared with placebo, suggesting an improvement with EPO therapy; however, no such improvement in other functional clinical outcomes (modified Rankin scale; Barthel index) was observed in this subgroup, calling into question the relevance of this observation.

The negative results for EPO administration in clinical trials remind us that all neuroprotective trials are hampered by the problem of delivery of a compound to a poorly perfused area of brain within a short time frame after stroke onset. Nonetheless, EPO could still have potential as an agent to improve functional outcome after stroke. For example, EPO has multiple restorative functions, including promoting angiogenesis and neurogenesis (FIG. 2D). ${ }^{101-103}$ To harness the restorative power of EPO in stroke, it is important to examine the mechanisms by which the temporal expression of endogenous EPO may be enhanced in astrocytes after stroke. Instead of direct administration of EPO, it may be more beneficial to avoid its potential systemic side effects by administering small molecules that can induce endogenous EPO 
expression in astrocytes. Prolyl hydroxylase inhibitors are compounds that induce expression of the HIFs and reduce stroke in animal models. ${ }^{29,104}$ Thus, use of similar compounds to induce EPO after stroke is one avenue of investigation for translational research.

\section{VEGF, MMPs, and astrocytes after stroke: divergent actions depend on temporal expression after stroke}

During hypoxia and after stroke, VEGF expression is induced by the transcription factor HIF-1 ${ }^{29,105}$. VEGF is expressed in astrocytes as well as other cell types. ${ }^{106,107}$ VEGF induces angiogenesis, ${ }^{108}$ has direct neuroprotective effects on neurons in culture, ${ }^{109}$ and is important for inhibiting delayed neuronal death several days after stroke $^{28}$ (FIG. 2E). VEGF has also been ascribed an important role in mediating the protection of hypoxic preconditioning. A neutralizing antibody against VEGF prevented the protection mediated by hypoxic preconditioning observed in vitro. ${ }^{110}$ In rats, hypoxic preconditioning was mirrored by an increase in VEGF levels in astrocytes. ${ }^{111}$ It should be noted, however, that astrocytes are not the sole source of VEGF in the brain. In fact, both microglia and neurons contribute to VEGF abundance after hypoxia. ${ }^{29,112}$ Therefore, the coordinated expression of VEGF by these multiple cell types likely contributes to its neuroprotective effect.

Although VEGF is neuroprotective under multiple hypoxia-ischemia paradigms, administration of VEGF at the onset of ischemia during stroke increases stroke volume by increasing edema ${ }^{41}$ (FIG. 1C). In contrast, when administered 2 days after stroke onset, VEGF enhances angiogenesis and recovery from stroke. Thus, the protective or pathological actions of VEGF is determined in part by its temporal expression. Similarly, an elegant study demonstrated that matrix metalloproteinase-9 (MMP-9) has pathological or adaptive functions depending on its temporal expression after stroke. ${ }^{28}$ The MMPs cleave extracellular matrix proteins, which are important in modulating cellular interactions during tissue remodeling in disease and trauma. MMP-9 increases bloodbrain barrier permeability and increases ischemia-induced damage during acute stroke (FIG. 1C). ${ }^{113,114}$ For example, MMP-9 knockout mice have less severe strokes and inhibitors of the MMP-9 reduce stroke volume. ${ }^{115} \mathrm{In}$ contrast, at several days after ischemia, MMP-9 serves a neuroprotective role by cleaving and activating VEGF (FIG. 2E). ${ }^{28}$ During this time frame, MMP is highly expressed on both astrocytes and neurons, and VEGF localizes primarily to astrocytes, suggesting that astrocytes contribute to this protective function of MMP-9. These temporally distinct and divergent actions of VEGF and MMPs demonstrate the important concept that molecules released by astrocytes may change from a pathological to adaptive phenotype, depending on the temporal profile of expression after ischemia. These temporal differences in function will need to be considered when designing clinical trials of neuroprotective agents.

\section{Astrocytes, $\mathrm{Cx} 43$, adenosine, and neuroprotection}

Astrocytes have a central role in controlling the extracellular concentration of adenosine, a molecule with known neuroprotective properties (FIG. 2C). ${ }^{116-119}$ The connexin $\mathrm{Cx} 43$ is expressed exclusively in astrocytes. Astrocytes release ATP through hemichannels formed by Cx43. ${ }^{120}$ The extracellular ATP released by astrocytes is converted to adenosine through the actions of ecto-nucleoside triphosphate diphosphohydrolases (NTPDase) and ecto $5^{\prime}$-nucleotidases (CD73). ${ }^{121}$

One recent study illustrates the absolute requirement of astrocyte-derived ATP and adenosine for hypoxic preconditioning-mediated neuroprotection. ${ }^{118}$ In a study using astroglioma cell lines, hypoxic preconditioning was ineffective at protecting astrocytes in the absence of the Cx43. Similarly, loss of $\mathrm{Cx} 43$ function in vivo eliminated hypoxic preconditioning-mediated protection in mice. ${ }^{118}$ Given that $\mathrm{Cx} 43$ is expressed only in astrocytes, this finding clearly implicates astrocytes as an important mediator of hypoxic preconditioning-derived neuronal protection.

Adenosine has direct neuroprotective effects on neurons through the $\mathrm{A} 1$ receptors by inhibiting adenylyl cyclase, inhibiting $\mathrm{Ca}^{2+}$ channels, and activating phospholipase $\mathrm{C}$, which diminishes neuronal death. ${ }^{122,123}$ In addition, A1 receptors on the presynaptic terminal can reduce synaptic release of glutamate. ${ }^{116}$ Because adenosine signaling also protects cultured astroglioma cells, astrocytes also are likely to mediate cell-autonomous protection by releasing ATP, which is subsequently converted to adenosine. ${ }^{118}$ Similarly, other studies implicate adenosine and enzymes that convert ATP to adenosine in ischemic preconditioning in the heart and kidney, ${ }^{124,125}$ suggesting a role for these pathways in mediating the protection provided by hypoxic preconditioning in multiple tissues.

Other observations suggest that A1 receptors and adenosine are neuroprotective in certain circumstances. For example, loss of A1 receptors increases seizures after traumatic brain injury. ${ }^{126}$ In addition, reducing adenosine concentration by overexpressing the main metabolic enzyme for adenosine, adenosine kinase, increases stroke volumes after transient MCAO. ${ }^{127}$ In contrast, other studies did not observe altered neuronal death with transient global ischemia in A1 knockout mice ${ }^{128}$; however, this may be due to compensatory changes, because the same study demonstrated that A1 antagonists increase damage after transient global ischemia.

Translating the neuroprotective qualities of adenosine to treatment of stroke patients has encountered several obstacles. ${ }^{119,123,129}$ One of the main hurdles is that A1 
receptors are widely expressed. For example, adenosine reduces conduction through the $\mathrm{AV}$ node of the heart, slowing heart rate. Adenosine also decreases blood pressure, causes sedation, and diminishes body temperature. ${ }^{123}$ Adding to the complexity is the fact that the different adenosine receptors may have divergent effects. ${ }^{119,123,129}$ For example, knockout of $\mathrm{A}_{2 \mathrm{~A}}$ receptors reduces stroke volume after transient MCAO. ${ }^{130}$ Similarly, $\mathrm{A}_{2 \mathrm{~A}}$ agonists increase glutamate release in the brain during ischemia. ${ }^{131,132}$ These results, of course, are the opposite of what would be predicted if adenosine had a neuroprotective action through its actions on the $A_{2 A}$ receptor. Because $A_{2 A}$ antagonists can be used with minimal effects on the cardiovascular physiology, $\mathrm{A}_{2 \mathrm{~A}}$ antagonists may be considered as neurotherapeutic agents in stroke. In fact, an $\mathrm{A}_{2 \mathrm{~A}}$ antagonist is now being examined in a clinical trial of patients with Parkinson's disease. ${ }^{133}$ Regardless, as can be appreciated, the temporal and spatial effects of the different adenosine receptors after stroke and the peripheral effects of different adenosine agonists and antagonists will have to be clearly elucidated if adenosine signaling is to be a target for translational therapies in stroke.

Beyond being a conduit for release of ATP from astrocytes, $\mathrm{Cx} 43$ also functions in gap junction communication, forming connections that likely modify tissue viability after stroke. This topic, which has been reviewed in detail elsewhere, ${ }^{134,135}$ is beyond the scope of the present review. It is nonetheless worth pointing out that carbenoxolone, a gap junction inhibitor, reduces neuronal death in focal and global models of ischemia in adult and neonatal rodents. ${ }^{136-138}$ Notably, carbenoxolone was used in the past to treat patients for ulcers $^{135,139}$; thus, it is tolerated in humans. The actions of carbenoxolone are not specific for gap junctions, however; carbenoxolone also blocks NMDA channels and voltage-sensitive $\mathrm{Ca}^{2+}$ channels, which may influence its effects on ischemic cell death. This calls into question the effect of astrocyte gap junctions during ischemia. Notably, knockout of Cx43 function produces an effect opposite to what would be predicted by the carbenoxolone experiments. That is, knockout of $\mathrm{Cx} 43$ function increases, not decreases, stroke volume. ${ }^{118,140}$

\section{Astrocytes encourage synaptic plasticity and recovery from stroke by release of thrombospondin}

Profound synaptic plasticity occurs after stroke in the peri-infarct cortex, which influences the recovery from stroke. ${ }^{141,142}$ Enhancing synaptic plasticity in the periinfarct cortex would likely improve functional outcome after stroke. Although initially presumed to be inactive bystanders, astrocytes have prominent roles in modifying synaptic plasticity and formation of new synapses. ${ }^{143,144}$ In some cases astrocytes likely inhibit neurite outgrowth by formation of a glial scar ${ }^{14}$ (see the article by Hamby and Sofroniew in this issue). The glial scar limits axon outgrowth by the expression of inhibitory molecules (proteoglycans) that form an unfavorable environment for axonal outgrowth (FIG. 1F).

In contrast, emerging evidence suggests that astrocytes also release extracellular matrix proteins that encourage neurite outgrowth and plasticity. For example, the thrombospondins 1 and 2 (TSP1/2), which are extracellular glycoproteins, are highly induced after stroke on astrocytes. ${ }^{145}$ In cultures of retinal ganglion cells, application of TSP1/2 enhances synaptogenesis severalfold, illustrating an important role of TSP $1 / 2$ for formation of synapses (FIG. 2F). ${ }^{146}$ To determine whether TSP1/2 may have a similar function after stroke, axonal plasticity and functional recovery were evaluated in TSP1/2 knockout mice. ${ }^{145}$ As would be predicted, synaptic number and axonal sprouting were reduced in mice lacking TSP1/2. Recovery on a tongue protrusion functional test after stroke was also diminished in these TSP1/2 knockout mice.

Based on these results, it might be proposed that designing treatments to increase TSP $1 / 2$ function could enhance stroke recovery. It should be noted, however, that thrombospondins are involved in a variety of functions and inhibit angiogenesis under some conditions, such as wound healing. ${ }^{147}$ Although TSP1/2 knockout mice did not show deficits in angiogenesis before or after stroke, ${ }^{145}$ these other roles will also need to be considered before considering TSP $1 / 2$ as targets for stroke therapy. Notably, gabapentin, an antiepileptic medication that is widely used for neuropathic pain control, inhibits the ability of TSP1/2 to increase synaptic density in cultures. ${ }^{148}$ Similarly, administration of gabapentin to neonatal rodents severely reduced the number of excitatory synapses. ${ }^{148}$ This finding should serve as a cautionary note in the treatment of stroke patients with gabapentin for neuropathic pain, in that this could potentially alter stroke recovery.

\section{Astrocytes and their putative contributions to functional recovery provided by stromal cells}

One of the more exciting emerging new therapies for improving functional recovery after stroke is the use of bone marrow-derived mesenchymal stromal cells (MSC). ${ }^{149,150}$ These are mixed population of cells containing progenitor and stem cells that are isolated from bone marrow and improve functional recovery in rodent stroke models when delivered several hours to days after stroke onset. ${ }^{149,150}$ Mesenchymal stromal cells can be obtained from adults and delivered intravenously. They are capable of homing to an area of ischemia by sensing stromal cell derived factor-1 (SDF1 ), which is highly expressed in ischemic tissue, with their CXCR4 receptors. Several pieces of evidence demonstrate that mesenchymal stromal cells enhance neurite plasticity after stroke. For example, mesenchymal stro- 
mal cells increase axonal density, reorient axonal growth, and increase transcallosal branching of axons into the contralateral cortex and contralateral sprouting of axons in the spinal cord. ${ }^{151}$

The mechanisms by which mesenchymal stromal cells execute their adaptive effects are still being delineated. The evidence nonetheless suggests that astrocytes have a prominent role. For example, mesenchymal stromal cells induce neurotrophic factor expression and release from astrocytes, including VEGF, brain-derived neurotrophic factor (BDNF), and basic fibroblast growth factor $(\mathrm{bFGF})^{152}$ (FIG. 2G). Moreover, mesenchymal stromal cells also diminish glial scar formation after stroke. Finally, recent data demonstrated that mesenchymal stromal cells diminish plasminogen activator inhibitor in astrocytes, which increases tPA expression in astrocytes. ${ }^{153}$ The increase in tPA enhanced neurite outgrowth in cultures, which was blocked when tPA function was reduced.

\section{SUMMARY}

Stroke is a leading cause of death and disability in the United States, and unfortunately there are limited options for stroke treatment. To date, neurotherapeutics have lacked efficacy at reducing stroke-induced damage or improving functional recovery. Although past work to develop neuroprotectants has focused on targeting neuronal mechanisms of cell death, this approach is flawed, given that astrocyte survival and function are critical determinants of neuronal survival and functional recovery after stroke. Thus, maintenance of supportive astrocyte function, such as release of EPO or adenosine, or limitation of pathological processes, such as inflammation and glutamate release, needs to be considered when designing future stroke neurotherapeutics. Recent work suggests that astrocytes also importantly contribute to angiogenesis, neuronal plasticity, and functional recovery in the several days to weeks after stroke. Given the delayed time frame during which putative treatments may be administered to enhance functional recovery after stroke, delineating the multiple processes by which astrocytes improve neuronal plasticity and functional recovery are particularly promising.

Acknowledgments: The work discussed in this review was supported in part by: 5K08NS046633 (D.A.R.), 1R01NS054192 (D.A.R.), and 1P01NS050315.

\section{REFERENCES}

1. Guo S, Lo EH. Dysfunctional cell-cell signaling in the neurovascular unit as a paradigm for central nervous system disease. Stroke 2009;40(3 Suppl):S4-S7.

2. Ransom B, Behar T, Nedergaard M. New roles for astrocytes (stars at last). Trends Neurosci 2003;26:520-522.

3. Iadecola C, Nedergaard M. Glial regulation of the cerebral microvasculature. Nat Neurosci 2007;10:1369-1376.
4. Chen Y, Swanson RA. Astrocytes and brain injury. J Cereb Blood Flow Metab 2003;23:137-149.

5. Kimelberg HK. Astrocytic swelling in cerebral ischemia as a possible cause of injury and target for therapy. Glia 2005;50:389397.

6. Anderson CM, Nedergaard M. Astrocyte-mediated control of cerebral microcirculation. Trends Neurosci 2003;26:340-344; author reply $344-345$.

7. Trendelenburg G, Dirnagl U. Neuroprotective role of astrocytes in cerebral ischemia: focus on ischemic preconditioning. Glia 2005;50:307-320.

8. Chesler M. Failure and function of intracellular $\mathrm{pH}$ regulation in acute hypoxic-ischemic injury of astrocytes. Glia 2005;50:398 406.

9. Dienel GA, Hertz L. Astrocytic contributions to bioenergetics of cerebral ischemia. Glia 2005;50:362-388.

10. Nedergaard M, Dirnagl U. Role of glial cells in cerebral ischemia. Glia 2005;50:281-286.

11. Giffard RG, Swanson RA. Ischemia-induced programmed cell death in astrocytes. Glia 2005;50:299-306.

12. Rossi DJ, Brady JD, Mohr C. Astrocyte metabolism and signaling during brain ischemia. Nat Neurosci 2007;10:1377-1386.

13. Asano T, Mori T, Shimoda T, et al. Arundic acid (ONO-2506) ameliorates delayed ischemic brain damage by preventing astrocytic overproduction of S100B. Curr Drug Targets CNS Neurol Disord 2005;4:127-142.

14. Sofroniew MV. Reactive astrocytes in neural repair and protection. Neuroscientist 2005;11:400-407.

15. Eroglu C. The role of astrocyte-secreted matricellular proteins in central nervous system development and function. J Cell Commun Signal 2009;3:167-176.

16. Panickar KS, Norenberg MD. Astrocytes in cerebral ischemic injury: morphological and general considerations. Glia 2005;50: 287-298.

17. Almeida A, Delgado-Esteban M, Bolaños JP, Medina JM. Oxygen and glucose deprivation induces mitochondrial dysfunction and oxidative stress in neurones but not in astrocytes in primary culture. J Neurochem 2002;81:207-217.

18. Vangeison G, Carr D, Federoff HJ, Rempe DA. The good, the $\mathrm{bad}$, and the cell type-specific roles of hypoxia inducible factor- $1 \alpha$ in neurons and astrocytes. J Neurosci 2008;28:1988-1993.

19. Swanson RA, Farrell K, Stein BA. Astrocyte energetics, function, and death under conditions of incomplete ischemia: a mechanism of glial death in the penumbra. Glia 1997;21:142-153.

20. Giffard RG, Monyer H, Choi DW. Selective vulnerability of cultured cortical glia to injury by extracellular acidosis. Brain Res 1990;530:138-141.

21. Giffard RG, Papadopoulos MC, van Hooft JA, Xu L, Giuffrida R, Monyer $\mathrm{H}$. The electrogenic sodium bicarbonate cotransporter: developmental expression in rat brain and possible role in acid vulnerability. J Neurosci 2000;20:1001-1008.

22. Liu D, Smith CL, Barone FC, et al. Astrocytic demise precedes delayed neuronal death in focal ischemic rat brain. Brain Res Mol Brain Res 1999;68:29-41.

23. Garcia JH, Yoshida Y, Chen H, et al. Progression from ischemic injury to infarct following middle cerebral artery occlusion in the rat. Am J Pathol 1993;142:623-635.

24. Lukaszevicz AC, Sampaïo N, Guégan C, et al. High sensitivity of protoplasmic cortical astroglia to focal ischemia. J Cereb Blood Flow Metab 2002;22:289-298.

25. Gürer G, Gursoy-Ozdemir Y, Erdemli E, Can A, Dalkara T. Astrocytes are more resistant to focal cerebral ischemia than neurons and die by a delayed necrosis. Brain Pathol 2009;19: 630-641.

26. Barrett KM, Ding YH, Wagner DP, Kallmes DF, Johnston KC; ASAP Investigators. Change in diffusion-weighted imaging infarct volume predicts neurologic outcome at 90 days: results of the Acute Stroke Accurate Prediction (ASAP) trial serial imaging substudy. Stroke 2009;40:2422-2427.

27. Du C, Hu R, Csernansky CA, Hsu CY, Choi DW. Very delayed infarction after mild focal cerebral ischemia: a role for apoptosis? J Cereb Blood Flow Metab 1996;16:195-201. 
28. Zhao BQ, Wang S, Kim HY, et al. Role of matrix metalloproteinases in delayed cortical responses after stroke. Nat Med 2006; $12: 441-445$

29. Baranova O, Miranda LF, Pichiule P, Dragatsis I, Johnson RS, Chavez JC. Neuron-specific inactivation of the hypoxia inducible factor $1 \alpha$ increases brain injury in a mouse model of transient focal cerebral ischemia. J Neurosci 2007;27:6320-6332.

30. Smith JM, Bradley DP, James MF, Huang CL. Physiological studies of cortical spreading depression. Biol Rev Camb Philos Soc 2006;81:457-481.

31. Shin HK, Dunn AK, Jones PB, Boas DA, Moskowitz MA, Ayata C. Vasoconstrictive neurovascular coupling during focal ischemic depolarizations. J Cereb Blood Flow Metab 2006;26:1018-1030.

32. Mies G, Iijima T, Hossmann KA. Correlation between peri-infarct DC shifts and ischaemic neuronal damage in rat. Neuroreport 1993;4:709-711.

33. Iadecola C, Alexander M. Cerebral ischemia and inflammation. Curr Opin Neurol 2001;14:89-94.

34. Iadecola C, Niwa K, Nogawa S, et al. Reduced susceptibility to ischemic brain injury and $N$-methyl-D-aspartate-mediated neurotoxicity in cyclooxygenase-2-deficient mice. Proc Natl Acad Sci U S A 2001;98:1294-1299.

35. Iadecola C, Zhang F, Casey R, Nagayama M, Ross ME. Delayed reduction of ischemic brain injury and neurological deficits in mice lacking the inducible nitric oxide synthase gene. J Neurosci 1997;17:9157-9164.

36. Endoh M, Maiese K, Wagner J. Expression of the inducible form of nitric oxide synthase by reactive astrocytes after transient global ischemia. Brain Res 1994;651:92-100.

37. Iadecola C, Zhang F, Xu S, Casey R, Ross ME. Inducible nitric oxide synthase gene expression in brain following cerebral ischemia. J Cereb Blood Flow Metab 1995;15:378-384.

38. Semenza GL. Regulation of oxygen homeostasis by hypoxiainducible factor 1. Physiology (Bethesda) 2009;24:97-106.

39. Chavez JC, Baranova O, Lin J, Pichiule P. The transcriptional activator hypoxia inducible factor 2 (HIF-2/EPAS-1) regulates the oxygen-dependent expression of erythropoietin in cortical astrocytes. J Neurosci 2006;26:9471-9481.

40. Jelkmann W, Wagner K. Beneficial and ominous aspects of the pleiotropic action of erythropoietin. Ann Hematol 2004;83:673-686.

41. Zhang ZG, Zhang L, Jiang Q, et al. VEGF enhances angiogenesis and promotes blood-brain barrier leakage in the ischemic brain. J Clin Invest 2000;106:829-838.

42. Harvey BK, Chang CF, Chiang YH, et al. HSV amplicon delivery of glial cell line-derived neurotrophic factor is neuroprotective against ischemic injury. Exp Neurol 2003;183:47-55.

43. Hermann DM, Kilic E, Kügler S, Isenmann S, Bahr M. Adenovirus-mediated GDNF and CNTF pretreatment protects against striatal injury following transient middle cerebral artery occlusion in mice. Neurobiol Dis 2001;8:655-666.

44. Kitagawa H, Sasaki C, Sakai K, et al. Adenovirus-mediated gene transfer of glial cell line-derived neurotrophic factor prevents ischemic brain injury after transient middle cerebral artery occlusion in rats. J Cereb Blood Flow Metab 1999;19:1336-1344.

45. Vahedi K, Hofmeijer J, Juettler E, et al.; DECIMAL, DESTINY, and HAMLET investigators. Early decompressive surgery in malignant infarction of the middle cerebral artery: a pooled analysis of three randomised controlled trials. Lancet Neurol 2007;6:215222.

46. Papadopoulos MC, Verkman AS. Potential utility of aquaporin modulators for therapy of brain disorders. Prog Brain Res 2008;170:589601.

47. Zador Z, Stiver S, Wang V, Manley GT. Role of aquaporin-4 in cerebral edema and stroke. Handb Exp Pharmacol 2009;(190): $159-170$.

48. Nielsen S, Nagelhus EA, Amiry-Moghaddam M, Bourque C, Agre P, Ottersen OP. Specialized membrane domains for water transport in glial cells: high-resolution immunogold cytochemistry of aquaporin-4 in rat brain. J Neurosci 1997;17:171-180.

49. Manley GT, Fujimura M, Ma T, et al. Aquaporin-4 deletion in mice reduces brain edema after acute water intoxication and ischemic stroke. Nat Med 2000;6:159-163.
50. Benfenati V, Nicchia GP, Svelto M, Rapisarda C, Frigeri A, Ferroni S. Functional down-regulation of volume-regulated anion channels in AQP4 knockdown cultured rat cortical astrocytes. J Neurochem 2007;100:87-104.

51. Feustel PJ, Jin Y, Kimelberg HK. Volume-regulated anion channels are the predominant contributors to release of excitatory amino acids in the ischemic cortical penumbra. Stroke 2004;35: $1164-1168$.

52. Zhang Y, Jin Y, Behr MJ, Feustel PJ, Morrison JP, Kimelberg HK. Behavioral and histological neuroprotection by tamoxifen after reversible focal cerebral ischemia. Exp Neurol 2005;196: 41-46.

53. Zhang Y, Milatovic D, Aschner M, Feustel PJ, Kimelberg HK. Neuroprotection by tamoxifen in focal cerebral ischemia is not mediated by an agonist action at estrogen receptors but is associated with antioxidant activity. Exp Neurol 2007;204:819-827.

54. Lakhan SE, Kirchgessner A, Hofer M. Inflammatory mechanisms in ischemic stroke: therapeutic approaches. J Transl Med 2009; 7:97.

55. Wang Q, Tang XN, Yenari MA. The inflammatory response in stroke. J Neuroimmunol 2007;184:53-68.

56. Bezzi P, Domercq M, Brambilla L, et al. CXCR4-activated astrocyte glutamate release via $\mathrm{TNF} \alpha$ : amplification by microglia triggers neurotoxicity. Nat Neurosci 2001;4:702-710.

57. Anderson CM, Swanson RA. Astrocyte glutamate transport: review of properties, regulation, and physiological functions. Glia 2000;32:1-14.

58. Rothstein JD, Dykes-Hoberg M, Pardo CA, et al. Knockout of glutamate transporters reveals a major role for astroglial transport in excitotoxicity and clearance of glutamate. Neuron 1996;16: 675-686.

59. Boycott HE, Dallas M, Boyle JP, Pearson HA, Peers C. Hypoxia suppresses astrocyte glutamate transport independently of amyloid formation. Biochem Biophys Res Commun 2007;364:100104.

60. Dallas M, Boycott HE, Atkinson L, et al. Hypoxia suppresses glutamate transport in astrocytes. J Neurosci 2007;27:39463955.

61. Taylor CT, Cummins EP. The role of NF- $\kappa \mathrm{B}$ in hypoxia-induced gene expression. Ann N Y Acad Sci 2009;1177:178-184.

62. Taylor CT. Interdependent roles for hypoxia inducible factor and nuclear factor- $\kappa \mathrm{B}$ in hypoxic inflammation. J Physiol 2008;586: 4055-4059.

63. Boycott HE, Wilkinson JA, Boyle JP, Pearson HA, Peers C. Differential involvement of TNF $\alpha$ in hypoxic suppression of astrocyte glutamate transporters. Glia 2008;56:998-1004.

64. Rothstein JD, Patel S, Regan MR, et al. $\beta$-Lactam antibiotics offer neuroprotection by increasing glutamate transporter expression. Nature 2005;433:73-77.

65. Chu K, Lee ST, Sinn DI, et al. Pharmacological induction of ischemic tolerance by glutamate transporter-1 (EAAT2) upregulation. Stroke 2007;38:177-182.

66. Lee SG, Su ZZ, Emdad L, et al. Mechanism of ceftriaxone induction of excitatory amino acid transporter-2 expression and glutamate uptake in primary human astrocytes. J Biol Chem 2008;283:13116-13123.

67. Lewerenz J, Albrecht P, Tien ML, et al. Induction of Nrf2 and $\mathrm{xCT}$ are involved in the action of the neuroprotective antibiotic ceftriaxone in vitro. J Neurochem 2009;111:332-343.

68. Yang GY, Zhao YJ, Davidson BL, Betz AL. Overexpression of interleukin-1 receptor antagonist in the mouse brain reduces ischemic brain injury. Brain Res 1997;751:181-188.

69. Fogal B, Li J, Lobner D, McCullough LD, Hewett SJ. System $x_{c}{ }^{-}$ activity and astrocytes are necessary for interleukin- $1 \beta$-mediated hypoxic neuronal injury. J Neurosci 2007;27:10094-10105.

70. Hara H, Friedlander RM, Gagliardini V, et al. Inhibition of interleukin $1 \beta$ converting enzyme family proteases reduces ischemic and excitotoxic neuronal damage. Proc Natl Acad Sci U S A 1997;94:2007-2012.

71. Ohtaki H, Takaki A, Yin L, et al. Suppression of oxidative stress after transient focal ischemia in interleukin-1 knock out mice. Acta Neurochir Suppl 2003;86:191-194. 
72. Mulcahy NJ, Ross J, Rothwell NJ, Loddick SA. Delayed administration of interleukin-1 receptor antagonist protects against transient cerebral ischaemia in the rat. Br J Pharmacol 2003;140:471476.

73. Rothwell N. Interleukin-1 and neuronal injury: mechanisms, modification, and therapeutic potential. Brain Behav Immun 2003;17:152-157.

74. Emsley HC, Smith CJ, Georgiou RF, et al. A randomised phase II study of interleukin-1 receptor antagonist in acute stroke patients. J Neurol Neurosurg Psychiatry 2005;76:1366-1372.

75. Matsui T, Mori T, Tateishi N, et al. Astrocytic activation and delayed infarct expansion after permanent focal ischemia in rats. Part I: enhanced astrocytic synthesis of S-100 $\beta$ in the periinfarct area precedes delayed infarct expansion. J Cereb Blood Flow Metab 2002;22:711-722.

76. Hu J, Ferreira A, Van Eldik LJ. S100 $\beta$ induces neuronal cell death through nitric oxide release from astrocytes. J Neurochem 1997;69:2294-2301.

77. Tateishi N, Mori T, Kagamiishi Y, et al. Astrocytic activation and delayed infarct expansion after permanent focal ischemia in rats. Part II: suppression of astrocytic activation by a novel agent $(R)$-(-)-2-propyloctanoic acid (ONO-2506) leads to mitigation of delayed infarct expansion and early improvement of neurologic deficits. J Cereb Blood Flow Metab 2002;22:723-734.

78. Pettigrew LC, Kasner SE, Gorman M, Atkinson RP, Funakoshi Y, Ishibashi H; Arundic Acid (ONO-2506) Stroke Study Group. Effect of arundic acid on serum S-100 $\beta$ in ischemic stroke. J Neurol Sci 2006;251:57-61.

79. Pettigrew LC, Kasner SE, Albers GW, et al.; Arundic Acid (ONO-2506) Stroke Study Group. Safety and tolerability of arundic acid in acute ischemic stroke. J Neurol Sci 2006;251:50-56.

80. Sorensen AG, Buonanno FS, Gonzalez RG, et al. Hyperacute stroke: evaluation with combined multisection diffusion-weighted and hemodynamically weighted echo-planar MR imaging. Radiology 1996;199:391-401.

81. Beaulieu C, de Crespigny A, Tong DC, Moseley ME, Albers GW, Marks MP. Longitudinal magnetic resonance imaging study of perfusion and diffusion in stroke: evolution of lesion volume and correlation with clinical outcome. Ann Neurol 1999;46:568-578.

82. Olivot JM, Marks MP. Magnetic resonance imaging in the evaluation of acute stroke. Top Magn Reson Imaging 2008;19:225230 .

83. Schwamm LH, Koroshetz WJ, Sorensen AG, et al. Time course of lesion development in patients with acute stroke: serial diffusion- and hemodynamic-weighted magnetic resonance imaging. Stroke 1998;29:2268-2276.

84. National Institute of Neurological Disorders and Stroke rt-PA Stroke Study Group. Tissue plasminogen activator for acute ischemic stroke. N Engl J Med 1995;333:1581-1587.

85. Marti HH, Gassmann M, Wenger RH, et al. Detection of erythropoietin in human liquor: intrinsic erythropoietin production in the brain. Kidney Int 1997;51:416-418.

86. Ruscher K, Freyer D, Karsch M, et al. Erythropoietin is a paracrine mediator of ischemic tolerance in the brain: evidence from an in vitro model. J Neurosci 2002;22:10291-10301.

87. Prass K, Scharff A, Ruscher K, et al. Hypoxia-induced stroke tolerance in the mouse is mediated by erythropoietin. Stroke 2003;34:1981-1986.

88. Masuda S, Okano M, Yamagishi K, Nagao M, Ueda M, Sasaki R. A novel site of erythropoietin production. Oxygen-dependent production in cultured rat astrocytes. J Biol Chem 1994;269:19488-19493.

89. Gruber M, Hu CJ, Johnson RS, Brown EJ, Keith B, Simon MC. Acute postnatal ablation of Hif- $2 \alpha$ results in anemia. Proc Natl Acad Sci U S A 2007;104:2301-2306.

90. Weidemann A, et al. The glial cell response is an essential component of hypoxia-induced erythropoiesis in mice. J Clin Invest 2009;119:3373-3383.

91. Morishita E, Masuda S, Nagao M, Yasuda Y, Sasaki R. Erythropoietin receptor is expressed in rat hippocampal and cerebral cortical neurons, and erythropoietin prevents in vitro glutamateinduced neuronal death. Neuroscience 1997;76:105-116.
92. Sakanaka M, Wen TC, Matsuda S, et al. In vivo evidence that erythropoietin protects neurons from ischemic damage. Proc Natl Acad Sci U S A 1998;95:4635-4640.

93. Liu J, Narasimhan P, Song YS, et al. Epo protects SOD2-deficient mouse astrocytes from damage by oxidative stress. Glia 2006;53: 360-365.

94. Diaz Z, Assaraf MI, Miller WH Jr, Schipper HM. Astroglial cytoprotection by erythropoietin pre-conditioning: implications for ischemic and degenerative CNS disorders. J Neurochem 2005; 93:392-402.

95. Bernaudin M, Marti HH, Roussel S, et al. A potential role for erythropoietin in focal permanent cerebral ischemia in mice. J Cereb Blood Flow Metab 1999;19:643-651.

96. Sirén AL, Fratelli M, Brines M, et al. Erythropoietin prevents neuronal apoptosis after cerebral ischemia and metabolic stress. Proc Natl Acad Sci U S A 2001;98:4044-4049.

97. Gonzalez FF, Abel R, Almli CR, Mu D, Wendland M, Ferriero DM. Erythropoietin sustains cognitive function and brain volume after neonatal stroke. Dev Neurosci 2009;31:403-411.

98. Sola A, Wen TC, Hamrick SE, Ferriero DM. Potential for protection and repair following injury to the developing brain: a role for erythropoietin? Pediatr Res 2005;57:110R-117R.

99. Ehrenreich H, Hasselblatt M, Dembowski C, et al. Erythropoietin therapy for acute stroke is both safe and beneficial. Mol Med 2002;8:495-505.

100. Ehrenreich H, Weissenborn K, Prange H, et al.; EPO Stroke Trial Group. Recombinant human erythropoietin in the treatment of acute ischemic stroke. Stroke 2009;40:e647-e656.

101. Shingo T, Sorokan ST, Shimazaki T, Weiss S. Erythropoietin regulates the in vitro and in vivo production of neuronal progenitors by mammalian forebrain neural stem cells. J Neurosci 2001; 21:9733-9743.

102. Sirén AL, Fasshauer T, Bartels C, Ehrenreich H. Therapeutic potential of erythropoietin and its structural or functional variants in the nervous system. Neurotherapeutics 2009;6:108-127.

103. Byts N, Sirén AL. Erythropoietin: a multimodal neuroprotective agent. Exp Transl Stroke Med 2009;1:4.

104. Siddiq A, Ayoub IA, Chavez JC, et al. Hypoxia-inducible factor prolyl 4-hydroxylase inhibition: a target for neuroprotection in the central nervous system. J Biol Chem 2005;280:41732-41743.

105. Rempe DA, Lelli KM, Vangeison G, Johnson RS, Federoff HJ. In cultured astrocytes, p53 and MDM2 do not alter hypoxia-inducible factor- $1 \alpha$ function regardless of the presence of DNA damage. J Biol Chem 2007;282:16187-16201.

106. Lee MY, Ju WK, Cha JH, et al. Expression of vascular endothelial growth factor mRNA following transient forebrain ischemia in rats. Neurosci Lett 1999;265:107-110.

107. Sinor AD, Irvin SM, Cobbs CS, Chen J, Graham SH, Greenberg DA. Hypoxic induction of vascular endothelial growth factor (VEGF) protein in astroglial cultures. Brain Res 1998;812:289291.

108. Beck H, Plate KH. Angiogenesis after cerebral ischemia. Acta Neuropathol 2009;117:481-496.

109. Jin KL, Mao XO, Greenberg DA. Vascular endothelial growth factor: direct neuroprotective effect in in vitro ischemia. Proc Natl Acad Sci U S A 2000;97:10242-10247.

110. Wick A, Wick W, Waltenberger J, Weller M, Dichgans J, Schulz JB. Neuroprotection by hypoxic preconditioning requires sequential activation of vascular endothelial growth factor receptor and Akt. J Neurosci 2002;22:6401-6407.

111. Bernaudin M, Nedelec AS, Divoux D, MacKenzie ET, Petit E, Schumann-Bard P. Normobaric hypoxia induces tolerance to focal permanent cerebral ischemia in association with an increased expression of hypoxia-inducible factor-1 and its target genes, erythropoietin and VEGF, in the adult mouse brain. J Cereb Blood Flow Metab 2002;22:393-403.

112. Plate KH, Beck H, Danner S, Allegrini PR, Wiessner C. Cell type specific upregulation of vascular endothelial growth factor in an MCA-occlusion model of cerebral infarct. J Neuropathol Exp Neurol 1999;58:654-666.

113. Jian Liu K, Rosenberg GA. Matrix metalloproteinases and free radicals in cerebral ischemia. Free Radic Biol Med 2005;39:71-80. 
114. Cunningham LA, Wetzel M, Rosenberg GA. Multiple roles for MMPs and TIMPs in cerebral ischemia. Glia 2005;50:329-339.

115. Asahi M, Asahi K, Jung JC, del Zoppo GJ, Fini ME, Lo EH. Role for matrix metalloproteinase 9 after focal cerebral ischemia: effects of gene knockout and enzyme inhibition with BB-94. J Cereb Blood Flow Metab 2000;20:1681-1689.

116. Wardas J. Neuroprotective role of adenosine in the CNS. Pol J Pharmacol 2002;54:313-326.

117. Heurteaux C, Lauritzen I, Widmann C, Lazdunski M. Essential role of adenosine, adenosine A1 receptors, and ATP-sensitive $\mathrm{K}^{+}$ channels in cerebral ischemic preconditioning. Proc Natl Acad Sci U S A 1995;92:4666-4670.

118. Lin JH, Lou N, Kang N, et al. A central role of connexin 43 in hypoxic preconditioning. J Neurosci 2008;28:681-695.

119. Williams-Karnesky RL, Stenzel-Poore MP. Adenosine and stroke: maximizing the therapeutic potential of adenosine as a prophylactic and acute neuroprotectant. Curr Neuropharmacol 2009;7:217-227.

120. Kang J, Kang N, Lovatt D, et al. Connexin 43 hemichannels are permeable to ATP. J Neurosci 2008;28:4702-4711.

121. Robson SC, Sévigny J, Zimmermann H. The E-NTPDase family of ectonucleotidases: structure function relationships and pathophysiological significance. Purinergic Signal 2006;2:409-430.

122. Boison D. Adenosine kinase, epilepsy and stroke: mechanisms and therapies. Trends Pharmacol Sci 2006;27:652-658.

123. Boison D. Adenosine and epilepsy: from therapeutic rationale to new therapeutic strategies. Neuroscientist 2005;11:25-36.

124. Grenz A, Zhang H, Hermes M, et al. Contribution of E-NTPDase1 (CD39) to renal protection from ischemia-reperfusion injury. FASEB J 2007;21:2863-2873.

125. Köhler D, Eckle T, Faigle M, et al. CD39/ectonucleoside triphosphate diphosphohydrolase 1 provides myocardial protection during cardiac ischemia/reperfusion injury [Erratum in: Circulation 2007;116:e514.]. Circulation 2007;116:1784-1794.

126. Kochanek PM, Vagni VA, Janesko KL, et al. Adenosine A1 receptor knockout mice develop lethal status epilepticus after experimental traumatic brain injury. J Cereb Blood Flow Metab 2006;26:565-575.

127. Pignataro G, Simon RP, Boison D. Transgenic overexpression of adenosine kinase aggravates cell death in ischemia. J Cereb Blood Flow Metab 2007;27:1-5.

128. Olsson T, Cronberg T, Rytter A, et al. Deletion of the adenosine A1 receptor gene does not alter neuronal damage following ischaemia in vivo or in vitro. Eur J Neurosci 2004;20:1197-1204.

129. von Lubitz DK. Adenosine and cerebral ischemia: therapeutic future or death of a brave concept? Eur J Pharmacol 1999;371: 85-102.

130. Chen JF, Huang Z, Ma J, et al. $A_{2 A}$ adenosine receptor deficiency attenuates brain injury induced by transient focal ischemia in mice. J Neurosci 1999;19:9192-9200.

131. O'Regan MH, Simpson RE, Perkins LM, Phillis JW. The selective A2 adenosine receptor agonist CGS 21680 enhances excitatory transmitter amino acid release from the ischemic rat cerebral cortex. Neurosci Lett 1992;138:169-172.

132. Popoli P, Betto P, Reggio R, Ricciarello G. Adenosine $A_{2 A}$ receptor stimulation enhances striatal extracellular glutamate levels in rats. Eur J Pharmacol 1995;287:215-217.

133. Stone TW, Ceruti S, Abbracchio MP. Adenosine receptors and neurological disease: neuroprotection and neurodegeneration. Handb Exp Pharmacol 2009;(193):535-587.

134. Farahani R, Pina-Benabou MH, Kyrozis A, et al. Alterations in metabolism and gap junction expression may determine the role of astrocytes as "good samaritans" or executioners. Glia 2005;50:351-361.

135. Juszczak GR, Swiergiel AH. Properties of gap junction blockers and their behavioural, cognitive and electrophysiological effects: animal and human studies. Prog Neuropsychopharmacol Biol Psychiatry 2009;33:181-198.

136. de Pina-Benabou MH, Szostak V, Kyrozis A, et al. Blockade of gap junctions in vivo provides neuroprotection after perinatal global ischemia. Stroke 2005;36:2232-2237.

137. Vakili A, Hosseinzadeh SA, Khorasani MZ. Peripheral administration of carbenoxolone reduces ischemic reperfusion injury in transient model of cerebral ischemia. J Stroke Cerebrovasc Dis 2009; 18:81-85.

138. Perez Velazquez JL, Kokarovtseva L, Sarbaziha R, Jeyapalan Z, Leshchenko Y. Role of gap junctional coupling in astrocytic networks in the determination of global ischaemia-induced oxidative stress and hippocampal damage. Eur J Neurosci 2006;23: $1-10$.

139. Turpie AG, Thomson TJ. Carbenoxolone sodium in the treatment of gastric ulcer with special reference to side-effects. Gut 1965; 6:591-594.

140. Nakase T, Söhl G, Theis M, Willecke K, Naus CC. Increased apoptosis and inflammation after focal brain ischemia in mice lacking connexin43 in astrocytes. Am J Pathol 2004;164:20672075.

141. Nudo RJ. Postinfarct cortical plasticity and behavioral recovery. Stroke 2007;38:840-845.

142. Carmichael ST. Plasticity of cortical projections after stroke. Neuroscientist 2003;9:64-75.

143. Hamilton NB, Attwell D. Do astrocytes really exocytose neurotransmitters? Nat Rev Neurosci 2010;11:227-238.

144. Barker AJ, Ullian EM. Astrocytes and synaptic plasticity. Neuroscientist 2010;16:40-50.

145. Liauw J, Hoang S, Choi M, et al. Thrombospondins 1 and 2 are necessary for synaptic plasticity and functional recovery after stroke. J Cereb Blood Flow Metab 2008;28:1722-1732.

146. Christopherson KS, Ullian EM, Stokes CC, et al. Thrombospondins are astrocyte-secreted proteins that promote CNS synaptogenesis. Cell 2005;120:421-433.

147. Kyriakides TR, MacLauchlan S. The role of thrombospondins in wound healing, ischemia, and the foreign body reaction. J Cell Commun Signal 2009;3:215-225.

148. Eroglu C, Allen NJ, Susman MW, et al. Gabapentin receptor $\alpha 2 \delta-1$ is a neuronal thrombospondin receptor responsible for excitatory CNS synaptogenesis. Cell 2009;139:380-392.

149. Li Y, Chopp M. Marrow stromal cell transplantation in stroke and traumatic brain injury. Neurosci Lett 2009;456:120-123.

150. Chopp M, Li Y. Treatment of neural injury with marrow stromal cells. Lancet Neurol 2002;1:92-100.

151. Liu Z, Li Y, Zhang ZG, et al. Bone marrow stromal cells enhance inter- and intracortical axonal connections after ischemic stroke in adult rats. J Cereb Blood Flow Metab 2010;30:1288-1295.

152. Gao Q, Li Y, Chopp M. Bone marrow stromal cells increase astrocyte survival via upregulation of phosphoinositide 3-kinase/ threonine protein kinase and mitogen-activated protein kinase kinase/extracellular signal-regulated kinase pathways and stimulate astrocyte trophic factor gene expression after anaerobic insult. Neuroscience 2005;136:123-134.

153. Xin H, Li Y, Shen LH, et al. Increasing tPA activity in astrocytes induced by multipotent mesenchymal stromal cells facilitate neurite outgrowth after stroke in the mouse. PLoS ONE 2010;5: e9027. 